\title{
Training Versatile Engineers: A Historical and Present Perspective on the Place of the Humanites and Social SCIENCES In THE CANADIAN EngINEERING ConteXT
}

\author{
John Donald ${ }^{\prime}$, Sofie Lachapelle ${ }^{2}$, Jacqueline McIsaac ${ }^{2}$, Tara Abraham ${ }^{2}$, Ryan Clemmer ${ }^{l}$, Karen Gordon ${ }^{1}$, \\ Stuart McCook ${ }^{2}$, and Richard G. Zytner ${ }^{1}$ \\ ${ }^{1}$ School of Engineering and ${ }^{2}$ Department of History, University of Guelph \\ *jrdonald@uoguelph.ca
}

\begin{abstract}
The importance of training well-rounded engineers has been discussed by engineering educators since the end of the Second World War. For decades now, the humanities and social sciences have been used to encourage engineering students to develop social competency, ethical awareness, and the ability to express themselves with ease, both orally and in writing. In Canada, the humanities and social sciences are featured prominently in the curriculum as part of complementary studies, which comprises both required and elective courses. How do students understand their experience with the humanities and social sciences during their degree? Do they see the usefulness of the skills and content learned in these fields for the job market? This study constitutes a first step in a larger project exploring these questions. Here we first present an overview of the historical and present debates on the place that humanities and social sciences have in the engineering curriculum. We then report on the feedback obtained from focus groups of graduating students asked about their experience and attitudes relative to "soft skills" graduate attributes and complementary studies. We conclude that the new Canadian Engineering Accreditation Board graduate attribute framework provides an opportunity to assess the role of the humanities and social sciences in the engineering curriculum and suggest possible ways to measurably enhance student experience and learning of non-technical or "soft" skills.
\end{abstract}

Keywords: Humanities, Social Sciences, Graduate Attributes, Complementary Studies, Soft Skills, Engineering, Careers.

\section{INTRODUCTION}

The engineering curriculum now includes the assessment of graduating student performance based on twelve program outcomes, or "graduate attributes" defined by the Canadian Engineering Accreditation Board (CEAB) [10]. These graduate attributes (GA) cover a wide range of the knowledge, skills and attitudes expected of an accredited Canadian Engineering program graduate, address a number of discipline-specific areas (such as engineering knowledge base and design) as well as nontechnical areas (such as communication, team work and lifelong learning). The CEAB also requires courses and/or content dealing with the central issues, methodologies, and thought processes of the humanities and social sciences. Complementary studies are often where these non-technical or "soft skills" are expected to be covered. Anecdotally, students often choose these courses without a plan and with a view to minimize their workload. Thus, from the perspective of both students and faculty, how successful are these courses in developing CEAB graduate attributes such as communication skills, professionalism, impact of engineering on society and the environment, ethics and equity, and life-long learning? This study constitutes a first step in a larger project exploring this question.

In recent years, a number of scholars and journalists have called for a greater collaboration between the humanities and STEM and, more precisely, for a greater partnership between engineering and the humanities as a way to foster greater cultural and social understanding and develop flexibility and adaptability in students. But what is the right level and approach to integrating the humanities and social sciences into the engineering curriculum? How do students understand their experience with these fields during their degree? Do they see the usefulness of the skills and content learned in their complementary courses for the job market? Are some of them interested in opportunities for greater exposure to the humanities and social sciences? What are the ways in which the value of complementary studies could be enhanced for engineering students?

Here, we begin by presenting an overview of the historical debates on the place of the humanities and 
social sciences in engineering education. We then discuss complementary studies in today's Canadian engineering curriculum. Finally, we report on the feedback obtained from focus groups of graduating students asked about their experience and attitudes relative to "soft skills" graduate attributes and complementary studies. We conclude that the new CEAB graduate attribute framework provides an opportunity to assess the role of the humanities and social sciences in the engineering curriculum and suggest possible ways to measurably enhance student experience and learning of non-technical or "soft" skills.

\section{HISTORICAL CONTEXT: A LITERATURE REVIEW}

\subsection{Training Socially-Conscious Engineers}

The place of the humanities and social sciences in the engineering curriculum has been a topic of discussion among engineering educators since the 1940s. Early on, the humanities were seen both as a means to enhance creativity and a potential tool against over-specialization [11][20]. Engineering educators appealed to the humanities as promoting more socially-conscious engineers. To be a good engineer, one had to be a good citizen, a state that could be achieved by studying the humanities, it was argued. By demonstrating an awareness of human history, ideas, and practices, engineers would be able to serve the public in a more complete way [34][38]. Calls for the inclusion of the human and social context in the engineering curriculum continued in the 1960s. For example, Norman Balabanian argued that the curriculum should prepare engineers "to participate intelligently in the affairs of his community. A person who is trained in a narrow engineering specialty, without emphasis on the scientific method and the broad social and philosophical implications of science and technology, will not develop the perceptions required to understand our world" [4]. For others, open-mindedness and social responsibility were necessary, but so was developing a life-long interest and respect for the arts [39].

\subsection{Bringing the Humanities in the Curriculum}

Concerns with communication skills and the nontechnical components of the engineering curriculum became apparent in the 1970s both in the US and Canada. William R. Grogan of the Worcester Polytechnic Institute fought the belief that "good engineering students are not interested in the humanities," which he considered a dangerous myth. So too was the assumption that engineering students were "inherently poor in verbal skills" To address this, he proposed that engineering students complete a minor in the humanities and a community engagement project. Grogan's counterpart at the University of Toronto, K.C. Smith, recommended teaching humanities and social science values through engineering-centric courses by instructors who were trained in both fields [25]. Many agreed that the humanities needed to be brought into the engineering curricula in more engaging ways. Syracuse University engineer Glenn Glasford, for example, lamented the lack of familiarity across both sides of the liberal arts and science divide and suggested designing a joint minor in liberal arts and scientific education for both engineers and non-engineers alike[22][33]. Significantly, a 1970s study conducted on European engineering programs found that in order for humanities or social sciences courses to influence engineering students, they had to be "fully integrated" into engineering curricula [5].

In 1981, chemist and editor of the Journal of Chemical Education J. J. Lagowski argued that "perceptive scientists are troubled by the realization that they are potential agents of unprecedented power but are not trained as arbiters of value. Many scientists suspect, and rightly so, that if their social predilections are allowed to influence their scientific judgment, they stand a real chance of doing poor, as well as potentially dangerous, science. Not only should we be aware of the common ground between the sciences and the humanities, we should also study it for the insights it can provide. We would probably be better scientists and better humans for the effort" [31]. A few years later, Steven Goldman reiterated that the value of the humanities lay in their ability to teach interpretation and critical thinking while asserting that engineers must consider how their own work will be used [23].

\subsection{Preparing Engineering Students for a Diverse Workplace}

Calls for holistic engineering education have included discussions of multidisciplinary courses and the need for increased contact with students from other disciplines as a way to mirror typical professional group settings and better train engineering students to face the ethical, economic, and social issues that often arise in the workplace [8][19][32]. Since the mid-1990s, some engineering educators have pushed for more English literature and creative writing courses [2]. Others have looked toward the history of science and technology as a way to instill important ethical and social lessons while fostering a better sense of how engineering work contributes to society [7][28]. By 2000, problem-based learning, historical case studies, and interdisciplinary courses were all encouraged as a way to provide students with opportunities to creatively solve problems and 
develop as ethical and socially responsible engineers and leaders [3][13][16][35]. This was largely in response to the criticism of many engineering educators, who believed that the ethics content in most engineering curricula was inadequate [9]. Historical case studies in addition to crossdisciplinary and discussion-based courses within the humanities and social sciences were considered an excellent way to teach ethics and leadership skills while also encouraging creativity. For instance, in 2008, philosopher Charles E. Harris Jr. promoted the inclusion of virtue ethics, a branch of ethics that focuses on the development of moral character instead of rules to follow [26]. The lack of effective communication skills among recent graduates and the role non-technical courses could play in alleviating the problem has also been a topic of interest [15][18][21][37].

In recent years, many engineering educators have stressed the importance of fostering engineers who are self-motivated, emotionally aware, and socially literate. These engineering graduates should be able to respond to a wide variety of social issues by developing selfawareness, cultural sensitivity, global understanding, and the ability to function in a multitude of social situations [6][12][14][29]. Many researchers and educators have stressed the benefits of problem-based learning, teambased learning environments, and multidisciplinary classes in teaching such skills [1][17][27][30][36][40].

\section{COMPLEMENTARY STUDIES IN CANADA: AN OVERVIEW}

In Canada, the CEAB requires students to take a minimum of 225 accreditation units (AU) in complementary studies defined to include humanities, social sciences, arts, management, engineering economics and communication. These courses must incorporate elements dealing with: the impact of technology on society, central issues, methodologies, and thought processes of the humanities and social sciences, oral and written communications, health and safety, professional ethics, equity and law, as well as sustainable development and environmental stewardship [10].

While program hours and objectives are the same, each institution can decide on its own approach. To understand the nature and variability of complementary studies, we reviewed the websites of the 43 Canadian institutions with accredited engineering programs [10]. For each accredited institution we considered the curricula, program descriptions, program guides, advertising strategies, and academic calendars available on the web.

\subsection{Complementary Courses Requirements and Offerings}

The number of compulsory and elective complementary studies courses varies across institutions, as does the range of courses engineering students can take to fulfill their complementary course requirements. Among compulsory complementary courses, business and economics are the most common and found in most schools. In addition, 33 institutions require an engineering and society course. Usually offered as a historical or philosophical survey, the course tends to be taught by external departments at larger institutions and engineering faculty at smaller ones. Communication courses are also widespread, with 27 institutions requiring at least one course in this field (either university writing, professional communication, or English literature). 18 institutions require ethics and law courses; and 4 schools require a course in environmental stewardship. Complementary studies electives also vary. Institutions such as the University of Toronto, York University, the University of Alberta, and the University of Guelph allot four or more complementary studies electives while some have no free complementary studies electives. When offered, the range of electives depends on institutions, and most engineering programs take advantage of resources at their institutions to offer courses in anthropology, geography, history, philosophy, women's studies, English, and classics. As a general trend, smaller and more specialized institutions offer a limited number of complementary study electives while larger and more educationally diverse institutions offer greater choice.

\subsection{Opportunities for Joint Programs or Additional Specializations}

Specializations, areas of concentration, minors, and joint degrees are offered at several institutions. The actual structure and credit requirement vary, but some general trends can be seen. The 9 institutions that offer joint degrees with the arts typically require students to apply to both programs independently and specify that a limited number of courses can be counted towards both degrees. For instance, Queens University and the University of Saskatchewan both specify that joint degree students must have 30 extra credits in their second degree field in order to successfully complete a dual program. Bishop's University and Université de Sherbrooke offer a dual engineering and liberal arts program in which students fulfill the engineering degree requirements from Sherbrooke but also take several general sciences and liberal arts courses at Bishop's. 18 engineering programs allow their students to take minors; of these, 10 specify that arts minors may be completed. A number of 
engineering programs offer options to develop business skills. For example, École de Technologie Supérieure offers both an Ebusiness option and an international engineering option, the University of Ottawa and Ryerson University both offer a management and entrepreneurship option, the University of Saskatchewan provides entrepreneurship or professional communications options, the University of Waterloo offers an engineering entrepreneurship option, and the University of Western Ontario allows its students to obtain a Global and Intercultural Engagement honour.

\subsection{Global Experience}

Study abroad programs and exchanges are possible at most institutions, but a few programs also advertise formal exchange programs with partner universities designed specifically for engineering students. For example, the University of Calgary allows small groups of mechanical engineers to study in Greece or China while its electrical engineers can visit Switzerland. The University of New Brunswick offers a German for Engineering Students program, exposing students to German language, culture, and history for four weeks. In addition, several institutions offer international development courses, specializations, or options to prepare their students for international work opportunities. The École de Technologie Supérieure, the Université du Québec à Trois-Rivières, and Queen's University offer international development courses, some of which can be counted towards their complementary studies requirements. The University of Western Ontario and the University of Waterloo offer international development as an area of concentration while York University offers an entire program in Engineering and International Development, resulting in a dual Bachelor of Applied Science and Bachelor of Arts degree over five years.

Several institutions offer language instruction for their students. Due to CEAB requirements, there is often a credit limitation in place for language courses, resulting in students only being able to take one or two language courses during their degree. French, German, Spanish, and Italian are the most common languages offered, but Ojibwe, Yiddish, Sanskrit, Hebrew, Arabic, and Japanese are also included at some institutions. Of note, Frenchspeaking programs often have an English language requirement in their engineering programs for professional development.

\subsection{Promoting Complementary Studies}

For the most part, complementary studies do not feature prominently in the promotion of engineering programs, but there are a few exceptions. The École
Polytechnique has a Centre of Complementary Studies (Centre des Études Complémentaires) that offers a comprehensive rational (including graduate attributes) for the curricular inclusion of economic, ethics, sociological, personal and relational units. Simon Fraser University widely advertises its integrated communications program, and Université de Sherbrooke stresses a problem-based learning approach to engineering education, both of which rely on the humanities and social sciences. McGill University calls the complementary studies within its programs "fundamental" while Université de Laval and Memorial University both claim that their complementary studies lead to socially conscious and creative engineers.

\section{COMPLEMENTARY STUDIES: THE STUDENT EXPERIENCE}

Given the demanding engineering curriculum, finding time and options for complementary studies remains challenging. That said, the review of websites summarized in the section above shows that many engineering schools in Canada are making targeted efforts to provide a variety of opportunities for exposing students to the social sciences and humanities either directly (through mandatory and elective complementary studies courses) or through other experiences such as problem-based learning, international opportunities and the introduction of non-engineering minors.

To develop a preliminary understanding of the impact of these efforts on engineering student experience and learning, we conducted, in Winter 2015, student focus groups with engineering students in the final year of their graduating program.

\subsection{Study Approach: Student Focus Groups}

The objective of the focus groups was to obtain a preliminary understanding of the engineering undergraduate experience of complementary studies courses in the context to the CEAB graduate attribute framework. As such, the main questions were structured specifically around the CEAB graduate attributes and the complementary study course experience. In addition, students were asked to discuss the place of cultural competency and versatility within their program.

Four focus groups, each 2 hours in length, were conducted; two at the University of Guelph, and two at the University of Waterloo. There were 14 student participants in total, 10 male and 4 female. The students were interviewed in groups of 3 to 4 and, given the depth and breadth of the discussions, the small individual focus group numbers proved to be appropriate and provided an excellent variety of responses and opinions. The engineering programs represented at each institution were 
Biomedical and Environmental from University of Guelph, and Civil, Environmental and Chemical from University of Waterloo.

\subsection{Focus Group Observations}

\section{CEAB "Soft Skill" Graduate Attributes}

A set of focus group questions was designed to gain student feedback on experience and self-perceived competency in the social sciences and humanities as it relates to the seven "soft skill" GA, namely:

6. Individual and Team Work

7. Communication skills

8. Professionalism

9. Impact of engineering on the society and the environment

10. Ethics and equity

11. Economics and project management

12. Lifelong learning.

Questions included "how important are these attributes to you?", "what kind of exposure did you have to them?", and "do you feel you need more or less exposure to these attributes?" In all focus groups, it became apparent that using the GA framework creates an awareness of the importance of the soft skills and allows students to reflect in a structured and fruitful way on the relative contributions made by difference aspects of their program, including the engineering courses, complementary studies courses and their experiences outside the classroom setting.

All students viewed proficiency in these seven graduate attributes as essential to becoming an effective engineering professional. In terms of their own experience of the curriculum, students felt that most of their exposure to the "soft skill" GA had come from their engineering courses, and in particular from their participation in design project courses, but recognized the role of complementary studies in enhancing their critical thinking and written communication skills as well as their ability to speak to both technical and non-technical audiences.

Students also noted the importance of activities set outside the classroom in learning the GA soft skills. Among them, coop was identified as key to developing and reinforcing each of the seven soft skill attributes and providing a tangible link between what is learned in the classroom and what is useful in the workplace. This became clear in comments such as "Coop is where we start to see problems in writing" (despite the significant amount of report writing required in courses). On risk and safety one student commented "I didn't know how important it was until I went into the workplace". With respect to professionalism and communication, another student said "You learn a lot from interviews, how to talk to people about yourself and your profession". Students also identified the positive role that participation in clubs, societies and other campus activities can have in the development of soft skills. This is not surprising, but it does indicate the value of coop and campus opportunities to the development of soft skills.

Finally, students emphasized the importance of models and the faculty's own behavior, stating several times that in order for them to truly internalize the soft skill GA, it is important for faculty members themselves to exemplify these skills. Examples provided included dress code and behavior (professionalism), keeping course material current and up-to-date (lifelong learning), effective lectures and presentations (communication skills), and adequate referencing of material (ethics).

Following our discussion of GA, we turned to complementary studies courses and their effectiveness in contributing to the development of the GA.

\section{Complementary Studies Courses}

We began the section on complementary studies (CS) by explaining the rationale for these courses in the context of the GA and the accreditation process. Questions then included "do you feel that the role of complementary studies has been explained sufficiently to you?", "did you enjoy these courses and how much time did you spend working on them?", "did you feel these courses were useful? what about now?", "what did you learn?", and "are there particular skills or topics that you feel could benefit you?"

In all focus groups, it rapidly became clear that students had generally placed little importance on their CS courses. They indicated that the purpose of the CS requirement had not been explained very clearly during their degree, nor had the courses themselves been presented as particularly relevant or important to their development. Some were even surprised to find out that the CS requirement was part of the accreditation process and not an institutional choice. Students generally felt that this lack of understanding had contributed to their attitude and approach to their CS requirement, that is, one of the "hurdles" to get over. This attitude was expressed in statements such as "the focus is on engineering courses. Unless you are interested in it, you just get by", and 'I only took them because I had to".

Many student-participants expressed an interest in greater guidance when choosing their CS courses. At both the University of Guelph and the University of Waterloo, students are required to select their elective CS courses from an approved list. And while students in our focus groups had all been very familiar with these lists and their content, many had still struggled with course selection. What course should they have taken and why? Now in their final semester and reflecting back on GA, they can see the potential usefulness of the CS courses and wish they had been provided with more information and greater guidance regarding their selection earlier in their degree. 
For some, there is the sense of a missed opportunity for valuable experience and skill development. For others who did make the effort to maximize the opportunities provided by the CS courses, there have been practical barriers. Students reported that, by its nature, the engineering degree makes it difficult to fully benefit from CS courses. Workload, particularly in the early years, makes students feel like they are in "survival mode". Students reported taking CS courses "that were easy, or will reduce workload" (for example, introductory courses with multiple choice tests and exams). Students contemplating graduate studies also pointed to their worry about their engineering GPA as greater than their desire for interesting CS courses, giving them another incentive to choose "easy" courses.

Beyond the pressures of the engineering curriculum, other logistical issues make it difficult for students trying to choose meaningful CS courses. Commonly identified issues are:

1. Scheduling: At both Guelph and Waterloo, the CS lists appear varied and long, but the engineering schedule makes it hard to find any space, and choice is in reality very limited. Students do have some options at night, but many report being tired after a full day of lectures and labs.

2. Accessibility: Popular courses fill quickly. Even if a course does fit in one's schedule, access can be limited.

3. Prerequisites: Access to many interesting upper-year courses require prerequisites, barring access to engineering students who have difficulties fitting specific courses into their schedule. CS courses often end up being first-year introductory courses, which in the words of one student is "not that productive".

For all these reasons, students reported feeling constrained to take at least some distance education (DE) courses. With respect to DE courses, the student feedback was mixed. While some did not like the experience, others stated "you get out what you put in".

Overall, and in the context of our discussion of GA, students did look back on their CS courses as encouraging critical thinking and forcing them "to think about different things outside of engineering". To improve the effectiveness of CS courses, they suggested:

1. Communicating the importance of CS courses for accreditation and employers early in the program

2. Developing tools to better guide students in their selection of CS courses and to help students plan and schedule their courses. This could include suggesting series of course related to a particular theme or skill.

3. Linking courses in the CS lists to specific GA

4. Providing opportunities for upper-year undergraduate to talk about their own experience of particular CS courses to lower-year cohorts. Students would like to hear from their peers about CS courses, not just their professors or program counsellors. Informal sessions could be organised.

5. Some students are interested in certificates: They are out there but students are generally not aware of them.

\section{Cultural Competency and Versatility}

A final group of questions dealt with cultural competency and versatility within the engineering degree in general and CS requirement in particular. Here, questions included "how much international exposure have you had? Is it important in today's job market?", "Do you feel that your degree has provided you with the versatility required in the job market? What role did complementary studies play in this?"

Students identified cultural competency as important but felt limited in their experience. Some students talked about the possibilities associated with a culturally-varied campus but also commented on the silo-ed mentality that often prevails. Others explained that while they did feel culturally "competent", this did not come from classroom, but rather from experience outside the classroom, most notably coop and the workplace. Interestingly, most groups also identified cultures with different disciplines outside engineering and discussed the CS courses as contributing to their cultural competence. They talked in particular of the humanities as a different world, often with greater percentage of female students. Commenting on a history course and depth and breadth of knowledge, one student said: "it was an eye-opener".

Although they planned to pursue a career in engineering, the students believe that their degree has provided them with a foundation that could allow them to pursue paths beyond engineering, a belief supported by one student who stated "many of my classmates took the MCAT or LSAT". Commenting on the process of making it through such a challenging program, another explained "it taught me how to learn".

\section{SUMMARY}

This study has been a first step toward a larger project on the place and value of CS in the engineering curriculum. The four focus group sessions with graduating students at the two different universities have provided valuable insight into the attitudes and behavior of students related to the $\mathrm{CS}$ requirement mandated of all Canadian accredited engineering programs. The CEAB soft skill GA provided an excellent framework to organize our discussions. Reflecting back on their undergraduate experience, the students demonstrated a strong grasp of the soft skill graduate attributes, yet saw their CS courses as a missed opportunity brought on by their lack of understanding of the purpose of these courses as well as 
practical challenges associated with the heavy workload and busy schedule of a demanding curriculum.

Given the effort that programs put toward creating CS lists that meet accreditation standards, students suggested that information and guidance beyond that presently available be provided. Understanding the importance of the CS courses for employers and the workplace, appreciating CS courses as an integral part of the GA, and obtaining some guidance from upper-year students would be beneficial. Equally important would be scheduled paths for CS courses early in their program, formal guidance in the form of online tools or guidebooks identifying particular CS themes (e.g. law, business, or ethics), and increased awareness of certificates or minors as a possibility. All of this would go a long way toward maximizing the value of, and appreciation for, CS courses.

\section{Acknowledgements}

The authors would like to acknowledge Katherine Sorensen, P. Eng., Program Counsellor, School of Engineering, University of Guelph, for her consultation and input on complementary studies criteria and implementation in engineering programs, Jason Grove, Ph.D., P.Eng., Chemical Engineering, University of Waterloo, for assistance in facilitating focus groups at the University of Waterloo, and Dale Lackeyram, Ph.D., University of Guelph Centre for Open Learning and Educational Support, for guidance on focus group design.

This study was supported by the Physical Science and Engineering Education Research (PSEER) Centre, at the University of Guelph.

This study has been reviewed and received ethics clearance through the University of Guelph and the University of Waterloo ethics committees.

\section{References}

[1]Alpay, E., A. L. Ahearn, and A. M.J. Bull. "Promoting Cross-Departmental Initiatives for a Global Dimension in Engineering Education: The Imperial College Experience." European Journal of Engineering Education 36, no. 3 (June 2011): 225-42.

[2]Arms, Valarie Meliotes, Sarah Duerden, Meredith Green, M. Jimmie Killingsworth, and Paul Taylor. "English Teachers and Engineers: A New Learning Community." International Journal of Engineering Education 14, no. 1 (1998): 30-40.

[3] Baggi, D. L. "The Need for Alternative Paradigms in Science and Engineering Education." European Journal of Engineering Education 32, no. 4 (August 2007): 441-49.

[4] Balabanian, Norman. "Thoughts on Engineering Education." Education, IRE Transactions on 4, no. 1 (1961): 6-8.

[5] Barron, A., D.E.P. Jenkins, and M. Bungard-Neilsen. "The Non-Technical Education of Engineers: Report of a
Working Party." European Journal of Engineering Education 2, no. 1 (January 1977): 65-72.

[6] Beddoes, Kacey D. "Feminist Scholarship in Engineering Education: Challenges and Tensions." Engineering Studies 4, no. 3 (December 2012): 205-32.

[7] Bissell, Christopher, and Stuart Bennett. "The Role of the History of Technology in the Engineering Curriculum." European Journal of Engineering Education 22, no. 3 (September 1997): 267-75.

[8] Bordogna, Joseph, Eli Fromm, and Edward W. Ernst. "Engineering Education: Innovation Through Integration." Journal of Engineering Education 82, no. 1 (1993): 3-8.

[9] Bucciarelli, L. L. "Ethics and Engineering Education." European Journal of Engineering Education 33, no. 2 (May 2008): 141-49. doi:10.1080/03043790801979856.

[10] Canadian Engineering Accreditation Board, "Accreditation Criteria and Procedures", (2014):13-35

[11] Cassidy, Harold G. "Chemistry, Chemical Engineering, and Culture." Journal of Chemical Education 32, no. 2 (1955): 86.

[12] Cech, Erin A., and Tom J. Waidzunas. "Navigating the Heteronormativity of Engineering: The Experiences of Lesbian, Gay, and Bisexual Students." Engineering Studies 3, no. 1 (April 2011): 1-24.

[13] Crosthwaite, C., I. Cameron, P. Lant, and J. Litster. "Balancing Curriculum Processes and Content in a Project Centred Curriculum." Education for Chemical Engineers 1, no. 1 (January 2006): 39-48.

[14] Cumming-Potvin, Wendy Marie, and John Currie. "Towards New Literacies and Social Justice for Engineering Education.” International Journal of Engineering, Social Justice, and Peace 2, no. 1 (2013): 21-37.

[15] Danilova, Elena A., and Zenon J. Pudlowski. "Important Considerations in Improving the Acquisition of Communication Skills by Engineers." Global J. of Engng. Educ 11, no. 2 (2007): 153-62.

[16] Ellis, Glenn W., A. N. Rudnitzky, and GAIL E. Scordilis. "Finding Meaning in the Classroom: Learner-Centered Approaches That Engage Students in Engineering." International Journal of Engineering Education 21, no. 6 (2005): 1148.

[17] Edström, Kristina, and Anette Kolmos. "Pbl and Cdio: Complementary Models for Engineering Education Development." European Journal of Engineering Education 39, no. 5 (September 3, 2014): 539-55.

[18] Finegold, Leonard. "Writing for Science as Scholarly Communication." Journal of Science Education and Technology 11, no. 3 (2002): 255-60.

[19] Florman, Samuel C. "Non-Technical Studies for Engineers: The Challenge of Relevance.” European Journal of Engineering Education 22, no. 3 (September 1997): 24958.

[20] Forbes, W. F., and G. M. Story. "Science and the Humanities: The Unity of Knowledge." Journal of Chemical Education 34, no. 12 (1957): 594.

[21] Ford, Julie Dyke, and Linda Ann Riley. "Integrating Communication and Engineering Education: A Look at Curricula, Courses, and Support Systems." Journal of Engineering Education 92, no. 4 (2003): 325-28. 
[22] Glasford, Glenn M. "The Focus of Engineering Education: The Student, the Profession, and Society." Education, IEEE Transactions on 13, no. 2 (1970): 65-69.

[23] Goldman, Steven L. "The Humanities in Science and Engineering Education.” Bulletin of Science, Technology \& Society 8, no. 1 (1988): 3-5.

[24] Gomes, V.G., G.W. Barton, J.G. Petrie, J. Romagnoli, P. Holt, A. Abbas, B. Cohen, et al. "Chemical Engineering Curriculum Renewal.” Education for Chemical Engineers 1, no. 1 (January 2006): 116-25.

[25] Grogan, William R., Chor Weng Tan, K.C. Smith, Basil R. Myers, and Thomas K. Gaylord. "Revamping the Nontechnical Part of the Curriculum." IEEE Transactions on Education E-22, no. 2 (May 1979): 48-52.

[26] Harris, Charles E. "The Good Engineer: Giving Virtue Its Due in Engineering Ethics." Science and Engineering Ethics 14, no. 2 (June 2008): 153-64.

[27] Hubbard, Ella-Mae, and Keith Gregory. "Supporting Multi-Discipline Undergraduate Group Projects.” Engineering Education 6, no. 2 (2011): 13-20.

[28] Jelen, Josef. "Technology, Science, Physics and Culture: Scientific View of the World as a Non-Technical Subject in Engineering Education." European Journal of Engineering Education 22, no. 4 (December 1997): 355-62.

[29] Joyner, Fredricka F., Derek TY Mann, and Todd Harris. "Engineering As A Social Activity: Preparing Engineers To Thrive In The Changing World Of Work." American Journal of Engineering Education (AJEE) 3, no. 1 (2012): 67-82.

[30] Kavanagh, Lydia, and John Cokley. "A Learning Collaboration Between Engineering and Journalism Undergraduate Students Prompts Interdisciplinary Behavior." Advances in Engineering Education 2, no. 3 (2011): 1-22.
[31] Lagowski, J. J. "What Can Scientists Learn from the Humanities?" Journal of Chemical Education 58, no. 9 (1981): 669.

[32] Lambrix, Patrick, and Ulla Ouchterlony. "Integration of Psychology, Economics and Information Technology in an Engineering Curriculum." Computer Science Education 9, no. 2 (1999): 162-80.

[33] Mathes, J. C., and Kan Chen. "Educational Objectives for Science, Technology, Society, and Values Programs." Education, IEEE Transactions on 21, no. 1 (1978): 27-30.

[34] Murphy, Walter J. "Chemistry and Chemical Engineering Curricula in the Postwar Era." Journal of Chemical Education 24, no. 8 (1947): 376.

[35] Newell, James A., and D. Cleary. "Using an Undergraduate Materials Research Project to Foster Multidisciplinary Teaming Skills.” Journal of STEM Education 5, no. 1 (2004): 18-23.

[36] Rectanus, Mark W. "Transdisciplinary Case Studies as a Framework for Working in Global Project Teams (2013)." Online Journal for Global Engineering Education 6, no. 1 (2013): 9.

[37] Riemer, Marc J. "Communication Skills for the 21st Century Engineer." Global J. of Engng. Educ 11, no. 1 (2007).

[38] Seely, Samuel. "Whither Electrical Engineering Education.” Education, IRE Transactions on 1, no. 2 (1958): 34-37.

[39] Warren, S. Reid. "The Status of the Humanities in Engineering Education.” Education, IEEE Transactions on 7, no. 2 \& 3 (1964): 69-71.

[40] Wisnioski, Matthew. "'Suppose the World Were Already Lost': Worst Case Design and the Engineering Imagination at Harvey Mudd College." Engineering Studies 6, no. 2 (May 4, 2014): 65-86. 